Research, Society and Development, v. 9, n. 10, e7079109250, 2020

(CC BY 4.0) | ISSN 2525-3409 | DOI: http://dx.doi.org/10.33448/rsd-v9i10.9250

\title{
A função do professor da hora-atividade na educação infantil: uma análise histórica
}

The teacher's role of hour-activity in early childhood education: a historical analysis

El papel del profesor de la actividad horaria en la educación infantil: un análisis

\section{histórico}

Recebido: 12/10/2020 | Revisado: 12/10/2020 | Aceito: 13/10/2020 | Publicado: 15/10/2020

Amanda Vitor Dourado

ORCID: https://orcid.org/0000-0003-2362-584X

Universidade Estadual de Maringá, Brasil

E-mail:amandav.dourado@gmail.com

Silvia Pereira Gonzaga de Moraes

ORCID: https://orcid.org/0000-0003-0937-5581

Universidade Estadual de Maringá, Brasil

E-mail: spgmoraes@uem

\section{Resumo}

Este estudo busca compreender a necessidade histórica da atuação do professor da horaAtividade. Para isso, foi realizada uma pesquisa de caráter documental, na qual analisou-se o processo histórico da constituição das leis que regulamentam a função do professor da hora atividade na Educação Infantil. A escolha dessa temática é justificada por trazer reflexões pertinentes sobre o trabalho docente, bem como a relevância de compreender a organização escolar para garantir a qualidade do ensino. Por meio das discussões e dos resultados obtidos, é possível perceber que as promulgações da Constituição Federal de 1988 e da Lei de Diretrizes e Bases (Lei 9394/96) - que contribuíram para a democratização do ensino e para a valorização do profissional da Educação - aliadas à luta docente e aos movimentos sindicais, resultaram na construção da Lei 11.738 de 16 de julho de 2008, em nível federal. Deste modo, os docentes conquistaram a hora-Atividade, isto é, um terço da carga horária de trabalho dos professores ficou destinado para a elaboração do planejamento das atividades, atendimento aos pais, alunos, realização de recursos, organização de materiais, formação e estudos. No entanto, para garantir esse importante direito aos docentes, foi preciso que os Estados e os Municípios reorganizassem suas políticas de rotina, contratação e destinação de verbas a fim de atender as novas demandas educacionais. Por exemplo, para organizar as disciplinas de 
forma que todos os docentes pudessem realizar o momento da hora-atividade, as escolas municipais incluíram na grade curricular as matérias de Inglês, Educação-Física, Arte, entre outras. Já as instituições de Educação Infantil organizaram oficinas com docentes, conhecidos como professores da hora-atividade/regente II/regente B, que atuassem, uma vez por semana, para suprir a carga-horária do professor regente. A história da atuação docente revelou a luta profissional do Magistério na conquista e na manutenção do direito da hora-atividade, advindo da mobilização dos trabalhadores da Educação. Isso demonstra que, por intermédio da história do passado e do presente, há a possibilidade de construir novas histórias no futuro, tendo em vista que a hora-atividade é uma condição de valorização do trabalho educacional e é de suma importância para garantir um ensino de qualidade. A pesquisa também demonstra que a conquista do direito da hora-atividade é uma luta contínua na busca do reconhecimento e da valorização dos profissionais da Educação Infantil.

Palavras-chave: Profissionais da educação; Professor hora-atividade; Educação Infantil; Trabalho.

\section{Abstract}

This all seeks to understand a historical need of the activity of the hour-activity teacher. For this, a documentary research was carried out, in which we analyzed the historical process of the laws that regulate funm fun'o of the teacher of the hour activity in the Children's Education. Or work justifies bringing reflections on or teaching work, to organize and the purpose of the school to ensure the quality of teaching. Results and argues that, according to the promulgation of the Federal Constitution-the Of 1988 and law of guidelines and bases (Law 9394/96), whose character of democratization of teaching and valorization, together with a professional mourning, in agreement with the union movements, resulted in the construction of Law 11,738 of July 16, 2008, at the federal level, which stabbed the teachers the Hour-Activity, that is, $1 / 3$ gives workload two teachers start to elaborate the planning of activities, assistance to parents, students, realization of resources, organization of materials, formacao and studies. Not in the meantime, to ensure that it is important for teachers and, inconsequence, a qualification of the student it was necessary for States and Municipalities to reorganize their routine policies and hiring, used funds to meet this demand. Thus, organize as disciplines for all teachers to perform or moment gives hourly activity, because municipal schools began to offer offices such as: English, Educação-Física, Art, among others and how institutions of Children's Education needed to organize offices with teachers, known as teachers of the hour-activity / regent II / regent B, which acts once a week to subdue the load 
time. In fact, it is considered that the history of the teaching act revealed the professional struggle of the Magisterium to guarantee and maintain the right of the hour-activity, coming from the mobilization of education workers, therefore, it demonstrates that through the history of the past, the present and that it still produces new stories in the future, which has in mind, the need for hour-activity as a condi'o and valorise of teaching work and a question of valuing this professional who seeks to guarantee or derito of the education of qualidad. The research also reveals the counter-activity between the conquest of the hour-activity right, as ruptures and brings the continuity of the struggles for the recognition and appreciation of these professionals of the Children's Education.

Keywords: Education professionals; Hour-activity teacher; Early childhood education; Labor.

\section{Resumen}

Todo esto busca entender una necesidad histórica de la actividad del maestro de actividad de horas. Para ello, se llevó a cabo una investigación documental, en la que analizamos el proceso histórico de las leyes que regulan la funm fun'o del profesor de la actividad de la hora en la Educación infantil. O el trabajo justifica traer reflexiones sobre el trabajo o la enseñanza, para organizar y el propósito de la escuela para asegurar la calidad de la enseñanza. Resultados y argumenta que, de acuerdo con la promulgación de la Constitución Federal-el de 1988 y la ley de directrices y bases (Ley 9394/96), cuyo carácter de democratización de la enseñanza y valorización, junto con un luto profesional, de acuerdo con los movimientos sindicales, dio lugar a la construcción de la Ley 11.738 de 16 de julio de 2008, a nivel federal, que apuñaló a los maestros la Hora-Actividad, es decir, 1/3 da carga de trabajo dos maestros comienzan a elaborar la planificación de actividades, asistencia a los padres, estudiantes, realización de recursos, organización de materiales, formacao y estudios. Mientras tanto, para asegurar que es importante para los maestros y, la inconsecuencia, una calificación del estudiante era necesario que los Estados y los Municipios reorganiza ras sus políticas rutinarias y la contratación, utilizaran fondos para satisfacer esta demanda. Así, organizarse como disciplinas para que todos los profesores realicen o el momento dé actividad cada hora, porque las escuelas municipales comenzaron a ofrecer oficinas como: Inglés, EducacaoFísica, Arte, entre otros y cómo las instituciones de Educación Infantil necesarias para organizar oficinas con maestros, conocidos como maestros de la actividad de horas / regente II / regente B, que actúa una vez a la semana para someter el tiempo de carga. De hecho, se considera que la historia del acto de enseñanza reveló la lucha profesional del Magisterio para garantizar y mantener el derecho de la actividad de las horas, viniendo de la movilización de 
los trabajadores de la educación, por lo tanto, demuestra que a través de la historia del pasado, el presente y que todavía produce nuevas historias en el futuro, lo que tiene en mente, la necesidad de la actividad de horas como condi'o y valorizar el trabajo docente y una cuestión de valorización de este profesional que busca garantizar o desconoarse de la educación de la calidad. La investigación también revela la contraactividad entre la conquista de la actividad de las horas correcta, ya que se rompe y trae la continuidad de las luchas por el reconocimiento y la apreciación de estos profesionales de la Educación Infantil.

Palabras clave: Profesionales de la educación; Profesor de actividad de horas; Educación Infantil; Trabajo.

\section{Introdução}

Em uma sociedade capitalista que presa pela produtividade, a hora-atividade do professor é vista como tempo ocioso e os governos, nas diferentes instâncias (federal, estadual e municipal), buscam brechas na lei para efetuar cortes em um direito historicamente conquistado.

Com o intuito de evitar o desmantelamento das conquistas trabalhistas do professor, é importante reconhecer e compreender o trabalho pedagógico realizado dentro e fora da sala de aula. Assim, observamos o cenário educacional do município de Maringá, Paraná, e levantamos as seguintes questões: "Quem são os profissionais da Educação Infantil em Maringá? Como se constitui o trabalho do professor no período de hora-atividade?”.

Para responder essas discussões, abordamos e problematizamos o trabalho na sociedade capitalista; o trabalho no processo de hominização e humanização; as relações de trabalho na atuação docente; os aspectos legais que estruturam a hora-atividade; a participação sindical; as lutas históricas que marcaram a consolidação da Lei 11.738/2008, fundamentando o piso salarial profissional nacional para os profissionais do magistério público da educação básica e a necessidade da hora-atividade na Educação Infantil.

Neste artigo, apresentaremos os resultados parciais da dissertação de mestrado intitulada: $O(A)$ professor(a) da hora-atividade na Educação Infantil. Nas primeiras pesquisas realizadas sobre a temática investigada, não encontramos estudos que abordassem as características, a importância e a função da hora-atividade para o professor da Educação Infantil. Assim, como o tema está diretamente relacionado com a categoria trabalhista, buscamos embasamento teórico nos estudos de Marx (1985/2013), Engels (1986), Leontiev (2004), Martins (2010), Moreira (2020) entre outros autores, articulando o trabalho na 
sociedade capitalista e o trabalho dos professores, em especial, da Educação Infantil.

Partimos do significado de trabalho, sob o prisma do Materialismo Histórico Dialético, abordando o processo de humanização/hominização para compreendermos como se estruturam os mecanismos trabalhistas e a atuação docente. Também investigamos os aspectos legais, organizacionais e a necessidade do cargo de professor de hora-atividade na Educação Infantil, bem como esses profissionais concebem e caracterizam o trabalho.

De acordo com Marx, o trabalho é categoria fundante para compreender o desenvolvimento humano e da sociedade (Marx \& Engels, 1989). Assim, o processo de hominização e humanização está relacionado com a atividade laboral que influenciou na diferenciação entre o ser humano e os outros animais: “[...] pela consciência, pela religião e por tudo que se queira. Mas eles próprios começam a se distinguir dos animais logo que começam a produzir seus meios de existência" (Marx; Engels,1989, p. 13). Com outras palavras, o ser humano é formado no/e pelo trabalho.

A atividade laboral não pode ser considerada apenas como fonte de riqueza, pois ela é essencial para a existência humana. Nesse processo, a natureza fornece a matéria prima e o ser humano a transforma. Marx e Engels (1989) defendem que o exercício do trabalho produziu a humanidade, pois ele “[...] é muitíssimo mais do que isso. É a condição básica e fundamental de toda a vida humana. E em tal grau que, até certo ponto, podemos afirmar que o trabalho criou o próprio homem" (Marx \& Engels, 1989 p.13).

De acordo com o valor de uso, os produtos possuem características diferentes entre si: "as mercadorias são, antes de tudo, de diferente qualidade; como valores de troca, elas podem ser apenas de quantidade diferente, sem conter, portanto, nenhum átomo de valor de uso" (Marx \& Engels, p. 98). Ainda, projetado o valor de uso das mercadorias, há o que se chama de propriedade - o produto do trabalho:

O produto não é mais uma mesa, uma casa, um fio ou qualquer outra coisa útil. Todas as suas qualidades sensíveis foram apagadas. E também já não é mais o produto do carpinteiro, do pedreiro, do fiandeiro ou de qualquer outro trabalho produtivo determinado. Com o caráter útil dos produtos do trabalho desaparece o caráter útil dos trabalhos neles representados e, portanto, também as diferentes formas concretas desses trabalhos, que não mais se distinguem uns dos outros, sendo todos reduzidos a trabalho humano igual, a trabalho humano abstrato (Marx \& Engels, 98-99).

Tendo em vista que o ser humano e o trabalho estão intrinsicamente relacionados, percebemos a necessidade de investigar como os profissionais da Educação Infantil se inserem na atividade laboral e quem são os profissionais que atuam para garantir os direitos 
dos docentes, pois esses são aspectos importantes para compreendermos a organização e a função social da Educação Infantil na formação das crianças.

Além disso, é relevante considerarmos a escassez de pesquisas, na área da Educação, que investigam as condições trabalhistas dos professores da Educação Infantil. Mesmo que alguns estudos tragam abordagens sobre a importância da hora-atividade para o trabalho docente, ainda há a necessidade de retratar a identidade deste profissional.

No levantamento de pesquisas realizadas nos bancos de dados de periódicos da Capes, BDTD e Google Acadêmico não foram encontradas publicações específicas que abordem as características dos professores de hora-atividade, com a exceção de dois estudos que mencionam o trabalho da classe docente. Portanto, faz-se necessário caracterizar esse profissional para compreender o trabalho exercido por ele com as crianças pequenas e possibilitar novas reflexões para futuras pesquisas sobre a organização do ensino e, assim, trazer contribuições para a qualidade da Educação.

\section{Metodologia}

O encaminhamento metodológico da pesquisa consiste no caminho percorrido pelo pesquisador para o estudo de um determinado objeto; no caso desta pesquisa, considera-se o percurso de análise da realidade objetiva do professor de hora-atividade, a fim de buscar o entendimento dos fenômenos reais e dos movimentos sociais.

Segundo Lima e Mito (2007), o pesquisador reflete sobre a interpretação formada diante do objeto. Com isso, ocorre uma releitura crítica dos conceitos reais que envolvem o objeto, de modo a integrá-los em sua pesquisa como algo positivo ou que possa ser superado. Em consequência, a pesquisa torna-se a essência das relações, dos processos, das estruturas e das representações ideológicas e/ou teóricas construídas sobre o objeto que o circunda.

$\mathrm{Na}$ primeira etapa desta pesquisa, realizamos um levantamento de estudos que abordam a questão do trabalho, o trabalho educativo, a valorização e a precarização do trabalho docente, o movimento de luta dos profissionais da Educação e a participação sindical.

Outro passo fundamental para a composição desta investigação é a fonte documental, na qual abordamos as legislações. Para realizar a análise dos documentos, recorremos aos autores da corrente Marxista, da Psicologia Histórico-Cultural e da Pedagogia HistóricoCrítica, com a intenção de compreender, de forma materialista e dialética, as características do(a) professor(a) de hora-atividade, no município de Maringá, em sua singularidade e 
particularidade para, posteriormente, universalizar a toda classe docente que se enquadra nessas condições de trabalho.

Para embasar a pesquisa, dentre as diversas vertentes do método dialético, adotamos a dialética Marxista, cujo propulsor foi Karl Marx (1818-1883), autor que defende o pressuposto de que é por meio das produções da vida e das relações sociais que o ser humano adquire diferentes relações de produção, as quais correspondem a uma determinada fase de desenvolvimento das suas forças produtivas materiais.

Marx considera o ser humano como um ser social, histórico e livre, mas que sofre intervenção devido à organização econômica: o capitalismo que utiliza interesses devidamente condicionados à economia, resultando na alienação dos sujeitos diante da realidade social, isto é, o ser humano é impelido a agir de acordo com os interesses capitalistas e não conforme suas vontades (Marx, 1985).

\section{Resultados e Discussão}

Como resultado das lutas históricas dos professores, instaura-se a Lei de Diretrizes e Bases da Educação (LDB)- lei no 9.394, de 20 de dezembro de 1996; e com a reivindicação de um momento reservado para as atividades extraclasse, institui-se a ideia de hora-atividade como uma forma de valorizar os trabalhadores do magistério. $\mathrm{O}$ artigo n. ${ }^{\circ} 67$, inciso $\mathrm{V}$, estabelece que os sistemas de ensino têm que promover a valorização dos profissionais da Educação, por meio de "estatutos e nos planos de carreira do magistério público e destinar período a estudos, planejamento e avaliação dentro da carga de trabalho" (Brasil, 1996).

Apesar da Lei de Diretrizes e Bases da Educação Nacional (1996) mensurar a necessidade de um período de atividades extraclasses, ainda não havia uma carga horária estipulada para a realização do cumprimento da hora-atividade. Cada Estado fixava uma porcentagem para o cumprimento da Lei, que variava entre $10 \%$ a $25 \%$ da carga horária reservada as atividades de planejamento. Ainda:

Não há dúvida de que a conquista da hora-atividade é resultado dos movimentos dos professores dos anos de 1980, nos quais as condições de trabalho docente foram exaustivamente denunciadas, gerando um movimento em defesa de um trabalho que oportunizasse a reflexão e a formação continuada em serviço (Goettert, 2014, p.62).

No Estado do Paraná, a LDBEN foi regulamentada pela Lei Estadual n 13807/2002. O Art. $3^{\circ}$ estabelece a hora-atividade "como período no qual o docente realiza funções da 
docência, reservado a estudos, planejamento das aulas, atendimento à comunidade escolar, avaliação dos alunos em ambiente de trabalho, entre outras" (Paraná, 2002).

Entretanto, vale ressaltar que houve significativas lutas, pelo movimento dos professores, na tentativa de ampliar a carga horária da hora-atividade. Tem-se ainda, a Lei Complementar n. 103/2004 que trata do Plano de Carreira do Professor da Rede Estadual de Educação Básica do Paraná, a qual preconiza que:

Art. 31. É garantida a hora-atividade para o Professor em exercício de docência, correspondente a $20 \%$ (vinte porcento) da carga horária do seu regime de trabalho. Parágrafo único - A hora-atividade deverá ser cumprida na escola, podendo ser cumprida fora da escola, excepcionalmente, em atividades autorizadas pela Secretaria de Estado da Educação, desenvolvidas no interesse da educação pública (Paraná, 2004).

No município de Maringá, lócus de realização dessa pesquisa, constatamos que a concessão de hora-atividade aos professores não diferiu muito. Em 1998, foi promulgada a Lei $n^{\circ}$ 272/1998 que regulamentou o plano de cargos, carreira e remuneração do magistério público municipal de Maringá, em seu Artigo 71, § $2^{\circ}$ define que:

[...] hora-atividade é o período de tempo efetivo de que disporá o professor, propriamente, para organização, preparação e encaminhamento do planejamento e avaliação, estudos, reunião pedagógica, articulação com a comunidade e aperfeiçoamento profissional, de acordo com a proposta pedagógica de Rede Municipal de ensino, a ser desenvolvida na unidade escolar, instituição educacional e/ou Órgão Municipal de Educação (Maringá, 1998).

No Artigo 73, da mesma lei, revela-se que o docente, em exercício da função em atividades na Educação Infantil ou no Ensino Fundamental, teria a jornada de trabalho organizada em: a) jornada de trabalho semanal de 20 horas, distribuídas em 16 horas de efetivo trabalho em sala de aula, mais 4 horas-atividade; b) jornada de trabalho semanal de 30 horas, distribuídas em 24 horas de efetivo trabalho em sala de aula, mais 6 horas-atividade (Maringá, 1998).

Com a promulgação da Lei ${ }^{\circ} 11.738$, de 16 de julho de 2008, em esfera federal, foi estabelecido a hora-atividade ou hora-pedagógica para os professores. Essa Lei determina que $33 \%$ (um terço) da carga-horária será destinada para a preparação das aulas, tirar dúvidas dos alunos, atender pais/responsáveis e estudar. O $\S 4^{\circ}$ apresenta que, "na composição da jornada de trabalho, observar-se-á o limite máximo de 2/3 (dois terços) da carga horária para o desempenho das atividades de interação com os educandos” (Brasil, 2008). 
Em 2009, foi estabelecida a lei complementar $n^{\circ} 790$ que determina o plano de cargos, carreira e remuneração do magistério público municipal de Maringá, revogando a lei complementar $n^{\circ} 272 / 98$ e suas posteriores alterações, abrangendo, então, no artigo 51:

A jornada de trabalho dos profissionais do magistério em função de docência será dividida, proporcionalmente à sua duração, em uma parte de atividades de interação com os alunos e outra parte em atividades complementares à docência, nos percentuais definidos pela legislação pertinente (Maringá, 2009).

Em 03 de julho de 2014, o Estado do Paraná aprovou a lei complementar 174/2014, implantando a complementação da hora-atividade para $33 \%$ de sua carga horária aos professores da Rede Estadual de Educação Básica do Paraná. Até a presente data desta pesquisa, o governo estadual atende a normativa na demanda do Ensino Fundamental.

A Educação Infantil é de responsabilidade integral dos municípios, assim, esses devem se organizar para o cumprimento da Lei Estadual. As formas de organização são diversificadas e, ainda, há municípios brasileiros que não atendem os dispositivos legais.

Em Maringá, os docentes da Educação Infantil são organizados da seguinte forma: professores regentes I e regente II; o professor regente II é aquele que substitui o regente I quando esse está em hora-atividade, por isso esse professor (regente II) também é chamado de professor de hora-atividade.

Defendemos que a hora-atividade docente é primordial para o trabalho do professor que visa a qualidade das suas ações pedagógicas, junto aos escolares, com o intuito de promover a aprendizagem e o desenvolvimento das crianças. Esse momento é destinado para o professor planejar suas aulas e rever seus trabalhos, condição fundamental para o adequado desenvolvimento do trabalho escolar.

A Lei complementar 174/2014 (que retrata a Lei da hora-atividade) instaurou, no artigo $2^{\circ}$, o piso salarial profissional nacional para os profissionais do magistério público da Educação Básica, também previsto no art. 62 da Lei nº 9.394, de 20 de dezembro de 1996, que estabelece as Diretrizes e Bases da Educação Nacional. Na mesma legislação, no $\S 4^{\circ}$, fica deferido que, na "composição da jornada de trabalho, observar-se-á o limite máximo de 2/3 (dois terços) da carga horária para o desempenho das atividades de interação com os educandos" (Brasil, 2008).

Observando a relação entre a legislação e o trabalho na sociedade capitalista, o labor é visto como emprego, no entanto, na teoria marxista, há uma diferença fundamental entre esses dois conceitos. Nessa circunstância, “[...] primeiramente o trabalho, a atividade vital, a vida 
produtiva mesma aparece ao homem apenas como um meio para a satisfação de uma carência, a necessidade de manutenção da existência física" (MARX, 2009, p.84). Essa diferença rege as relações de trabalho na sociedade capitalista e o ser humano, que não dispõe dos meios de produção para produzir sua subsistência, vende a única forma de "mercadoria" que possui: a força laboral.

Com as transformações das relações do capital, o sujeito - que historicamente estava relacionado ao trabalho - passa a se desconectar da sua produção e, muitas vezes, não tem acesso àquilo que ele mesmo produz. A sua força de trabalho é trocada por um salário que, na maior parte das vezes, mal satisfaz suas necessidades básicas.

Segundo dados do Departamento Intersindical de estatística e estudos socioeconômicos-DIEESE (2019), o salário mínimo nominal é de R\$1.039,00, entretanto, pesquisando o impacto da cesta básica durante as perdas salariais, para atingir o objetivo da origem do salário mínimo, esse deveria ser no valor de $\mathrm{R} \$ 4.347,61$.

A Constituição Brasileira estabelece, no art. $6^{\circ}$, como direito de todo cidadão, “[...] a educação, a saúde, a alimentação, o trabalho, a moradia, o transporte, o lazer, a segurança, a previdência social, a proteção à maternidade e à infância, a assistência aos desamparados" (Brasil, 1990, art. 6º. No entanto, há uma contraposição entre o que é defendido na Constituição e o que é praticado nas relações capital-trabalho, pois, na sociedade capitalista, há a necessidade de produzir mercadoria para ser vendida e obter lucros. Desse modo, “a utilidade de uma coisa faz dela um valor de uso" (Marx, p. 97).

Os proprietários do meio de produção, com o intuito de sempre permanecerem no poder, se articulam por diferentes mecanismos de alienação das camadas populares. Em outras palavras, a elite burguesa comanda, em altos cargos, a direção da educação das massas, a indústria cultural e as tecnologias em benefício de si próprio.

Com o discurso democrata, a elite se apodera de termos do pensamento político da esquerda - caracterizados pela defesa da igualdade social - para justificar a ação política direitista, embasada na tradição religiosa cristã e no liberalismo econômico, que são contraditórios, pois, ao mesmo tempo que prega a igualdade para todos, prevalece uma educação popular de comodismo diante das injustiças sociais.

Para Bobbio, Matutei e Pasquino (1999), o sistema capitalista se diferencia de outros modelos de produção. Por intermédio da distribuição e do consumo histórico, o mercado é regulado pela iniciativa privada, com enaltecimento e racionalização dos meios e dos métodos à elevação do capital e do reconhecimento das possibilidades do mercado para a obtenção do lucro. 
Assim, para a aquisição do lucro, a alienação humana é, na maioria das vezes, praticada e propagada por quem possui poder na sociedade capitalista. $\mathrm{O}$ ato de alienar consiste no desinteresse dos trabalhadores pelos acontecimentos sociais ou quando o sujeito não se reconhece na totalidade da sua realidade - o que é excelente para quem quer dominar ou continuar comandando os grupos sociais.

Os trabalhadores não são incentivados a desenvolverem o pensamento crítico e, consequentemente, não refletem sobre suas condições de vida, aceitando condições mínimas e desumanas de sobrevivência.

O trabalho é fundamental para a dignidade humana. De acordo com Marx (1983), quando os sujeitos perdem o controle do labor, a sociedade se transforma em uma ordem social alienada, com expressiva desigualdade, pobreza diante de muitos recursos e má distribuição, divergências sociais e luta de classes.

A alienação também se manifesta, segundo Marx (1983), na relação de estranhamento entre o trabalhador e o produto de sua atividade laboral que pertence ao dono do meio de produção. Nesta perspectiva, o trabalho é uma ação forçada e, não obstante, determinado pela necessidade extrema e pela exploração.

Um fenômeno particular da alienação no capitalismo é denominado de fetichização: o valor de uma mercadoria é dado pelo trabalho real corporificado e pelas condições médias de produção da sua indústria (Schlesener; Masson; Subtil,1997, p.250). Em suma, o labor deixa de satisfazer as necessidades de desenvolvimento humano do trabalhador e passa a ser uma forma de desempenhar as inevitabilidades externas a ele. Assim:

(...) o ponto de vista deste capitalismo voraz é o homem engendrado por suas próprias relações; isto é, o homem despersonalizado, desumanizado, oco por dentro, esvaziado de seu conteúdo concreto e vivo, que pode se deixar modelar facilmente por qualquer manipulador de consciências; em suma, o homem-massa (Vázquez, 1978, p. 27).

No decorrer das mudanças sociais, que perpassaram diferentes fases do capitalismo (comercial ou mercantil/pré-capitalismo, do século XV ao XVII; industrial ou Industrialismo, nos séculos XVIII e XIX; e Financeiro/monopolista, a partir do século XX até a atualidade), surgiram as frentes sindicais, com o intuito de defender os direitos trabalhistas, pois, com a intensão de obter grandes lucros, os donos dos meios de produção passaram a explorar cada vez mais os trabalhadores.

O mesmo aconteceu com os profissionais da Educação que quanto mais vendiam mão de obra, mais perdiam seus direitos. Como consequência da modernização industrial 
conservadora, o desmonte do Estado de Bem-Estar econômico e social e a desregulamentação dos mercados, organizados dentro do ideal das políticas neoliberais, foram fatores que permitiram o descontentamento operário e o resultado da crise atual (Prado, 2020).

O trabalhador e a Educação estão ligados ao viés capitalista e aos princípios neoliberais, de modo que as políticas sociais, econômicas, culturais e educacionais direcionam a sociedade à adaptação conformista, sem questionamentos e reflexões sobre a atuação profissional e a formação humana para as atividades laborais (Proni, 1997).

Marx (1985) apresenta a relação capital-trabalho em três fases centrais: na primeira fase, os sujeitos possuíam "a unidade imediata e mediata de ambos", compreendido como o momento de união, fendem-se e retornam-se singulares um ao outro, porém, certificando-se respectivamente em condições positivas. Na segunda fase, há "a oposição de ambos", os sujeitos se excluem entre si, o operário vê o patrão como a negação da sua existência. $\mathrm{Na}$ terceira fase, há "a oposição de cada um contra si mesmo", na qual o capital é, ao mesmo tempo, o trabalho (acumulado) e o modo de sobrevivência humana, ou seja, ele é o seu próprio oposto contraditório.

Diante dos conflitos na busca por melhores condições de trabalho e nas formas de políticas neoliberais, que desvalorizavam as atividades do trabalhador, foram instituídas organizações que promoveram melhorias, como o auxílio-mútuo e de socorro, com o objetivo de amenizar os períodos difíceis vividos por operários em situações de acidentes. Outra medida tomada pelas ações sindicais foi a criação das Uniões Operárias que, com a indústria, passou a se organizar de acordo com os diferentes ramos de atividade. Assim, surgiu o movimento sindical no Brasil (Goettert, 2014).

Mundialmente, as lutas históricas são realizadas para melhorar as condições sociais da classe trabalhadora, mesmo que a intenção da classe burguesa seja desmantelar as organizações do proletariado. Em 1824, durante a incessante busca por espaço social e por valorização no trabalho, foi estabelecido a associação dos trabalhadores (que antes era concedido apenas à elite dominante), pelo governo inglês. Com relação as ações sindicais, Engels pontua:

(...) graças à ação sindical, a lei dos salários se impôs pela força aos patrões capitalistas. Com efeito, bem organizados, os operários de todos os ramos da indústria podem receber - ao menos aproximadamente - o justo valor da força de trabalho que alugam e, com ajuda da legislação do estado, fixar o tempo de trabalho, para que não exceda sua duração máxima (...) (Engels, 2008, p. 72). 
Como afirma Engels (2008), a partir das ações sindicais, o trabalhador começou a receber um valor mais justo pela sua mão de obra. Além disso, foram criadas as leis do Estado para garantir e fazer valer condições dignas de trabalho. Logo mais, desenvolveram-se as organizações sindicais, equivalentes aos atuais sindicatos:

Isso não quer dizer que os sindicatos tenham surgido a partir dessa lei. Ao contrário, as associações sindicais já existiam na Inglaterra desde o século XVIII, mas eram violentamente reprimidas no desempenho de suas atividades, dificultando a organização operária. A aprovação da lei, no entanto, não deve ser considerada uma concessão dos capitalistas, que, fazendo uso da caridade e da benevolência, garantiram o direito à associação aos trabalhadores e trabalhadoras. Muito além disso, esse direito foi uma conquista dos trabalhadores e trabalhadoras ingleses a partir de lutas, nem sempre pacíficas (Goettert, 2014, p.45).

\section{O sindicalismo e a luta docente}

Nas palavras de Marx (2008), os “[...] sindicatos têm por fim impedir que o nível de salários desça abaixo da soma paga tradicionalmente nos diversos ramos da indústria e que o preço da força de trabalho caia abaixo de seu valor" (Marx, 2008, p. 65). A ação sindical, durante sua atuação histórica, buscou auxiliar na fiscalização e na implementação da fixação de salários e regulamentou que o lucro resulta no acréscimo da produtividade industrial, portanto, é direito do trabalhador receber uma ampliação salarial.

Outras ações, em prol da valorização do trabalhador, foram a constituição dos fundos de auxílio aos operários, em períodos de adversidades, e a união das categorias de determinada localidade em uma só federação. Em 1830, os operários ingleses fundaram a Associação Nacional à Proteção do Trabalho, que constituiu a centralidade entre os sindicatos (Goettert, 2014).

No Brasil, não foi diferente, pois a classe trabalhadora brasileira foi influenciada pelas organizações sindicais europeias, advindas de imigrantes, oriundos da Europa, no século $\mathrm{XIX}^{1}$. O perfil político-ideológico sindical era estabelecido conforme o pertencimento dos partidos políticos. Não obstante, com a ditadura militar, no governo de Getúlio Vargas (1882 —1954) $)^{2}$, em 1930, houve a submissão dos sindicatos ao controle do Estado e a fundação do Ministério do Trabalho (Mattos, 2009).

\footnotetext{
1 Período em que a economia brasileira passou por grandes transformações: a abolição da escravatura e a Proclamação da República.

${ }^{2}$ Getúlio Vargas, ainda foi responsável pela Consolidação das Leis do Trabalho (CLT) e dos institutos de Previdência Social.
} 
O decreto 19.770, de 1931, normatizou a atuação do Ministério do Trabalho nas assembleias sindicais; determinou que as ações políticas e ideológicas não fossem comedidas pelas organizações sindicais; colocou-se contrário à filiação de trabalhadores aos sindicatos internacionais; inibiu a sindicalização de funcionários públicos; e declarou a restrição da atuação operária dos estrangeiros nas ações sindicais (Texeira, 2009).

Em 1940, houve manifestações intensas, contudo, apenas em 1960, a luta sindical atingiu seu auge com o marco do III Congresso Sindical Nacional, que determinou o Comando Geral dos Trabalhadores (CGT). Entretanto, com o golpe militar em 1964, o movimento dos trabalhadores novamente foi repreendido e dirigido pelo Estado (Araújo, 2015).

Em 1970, o sindicalismo voltou a atuar no campo das lutas mais intensas, por exemplo, retomou as greves nas fábricas no estado de São Paulo. Neste período, a principal motivação da greve foi o requerimento de reposição dos $31 \%$ dos salários que o governo, até então, não realizava, acompanhando os índices de inflação. A manobra foi pronunciada pelo Banco Mundial, em meados de 1977, e resultou na insatisfação da classe trabalhadora.

Segundo Teixeira (2009), a intensificação das lutas sindicais, nos anos de 1970, instituiu o movimento operário no contexto político, econômico e social brasileiro, com a instauração da Central Única dos Trabalhadores (CUT) e do Partido dos Trabalhadores (PT). A partir de 1980, esses grupos organizaram greves gerais e desempenharam funções significativas em movimentos políticos, por exemplo, as Diretas Já, que tinha por objetivo a retomada das eleições diretas para a presidência da República no Brasil.

Assim como os operários se organizaram em sindicatos para a melhoria das condições de trabalho e para a valorização da profissionalização, os profissionais da Educação também se organizaram. De acordo com Oliveira (2010), no final de 1970, houve a construção do sindicalismo docente, com intensa manifestação dos professores em busca de valorização e de profissionalização do magistério. Entre as reinvindicações estava o reconhecimento social e econômico, diante da limitada autonomia e da desqualificação labora, pois, até então, a educação era vista como uma vocação ou sacerdócio.

O movimento de luta dos professores foi desencadeado a partir da tomada de consciência de que eles eram profissionais da Educação, portanto, trabalhadores que necessitavam de boas condições de trabalho. Assim, uma parcela dos docentes passa a filiarse aos sindicatos.

Após intensas lutas, foi instaurada a Constituição Federal de 1988, no período da redemocratização. Com isso, o movimento sindical ganhou mais liberdade, pois já não era 
necessária a autorização do Ministério do Trabalho para o exercício sindical, o que culminou na participação dos servidores públicos ao sindicato.

Alguns problemas da era varguista ainda perduram: imposto obrigatório e a unicidade sindical. Essas estruturas continuam em debate na atualidade, pois há o questionamento dos benefícios dos trabalhadores e se há a necessidade da reforma sindical (Teixeira, 2009).

Para a instauração da hora-atividade dos professores, diversas lutas históricas foram mobilizadas, pois, apesar do docente ser necessário e peça fundamental para o desenvolvimento da sociedade, ele é considerado mercadoria para aqueles que regem as políticas na sociedade brasileira.

Entre os enfrentamentos vivenciados pelos profissionais da Educação, destacam-se: as relações sociais no trabalho; a remuneração; a formação; a hora-atividade; as políticas públicas voltadas à valorização dos professores; e as melhorias nas condições de trabalho.

As atividades laborais, nas diferentes modalidades de ensino, implicam, ao professor, "[...] dificuldades na interação social com os grupos onde trabalha, a insatisfação com as condições de trabalho, a desvalorização social e os sentimentos de insegurança em relação à sua integridade física [...]" (Prado, 2013, p. 6) - fatores que foram razões para a movimentação sindical.

A insatisfação com as condições de trabalho desencadeou a busca pela valorização profissional dos docentes, os quais lutaram, junto ao sindicato, e pressionaram o Congresso Nacional para instaurar a Lei 11.738/2008. Atualmente, é essa Lei que regulamenta o piso salarial profissional nacional para os profissionais do magistério público da Educação Básica e prevê $1 / 3$ da hora-atividade para os professores realizarem suas atividades. Instaurada nos Estados, logo os profissionais da Educação e as centrais sindicais se organizaram para fazer valer a Lei.

Ao conquistarem tal direito, houve a necessidade de reorganização dos sistemas de ensino no âmbito federal, estadual e municipal, com o objetivo de atender a legislação. No que se refere a Educação Infantil, em especial no município de Maringá, para que o professor regente tivesse o direito da hora-atividade, foi contratado outro profissional, denominado professor regente II - investigar como esse profissional se insere na organização dos trabalhos na Educação Infantil é o foco principal dessa pesquisa em andamento.

Acreditamos que conhecer o percurso histórico, realizando um estudo dialético entre as conquistas trabalhistas e a inserção de leis que garantem os direitos da classe docente, é fundamental para compreendermos a singularidade, as características do professor de horaatividade e como essas se relacionam com as formas universais do trabalho humano. 


\section{Considerações Finais}

Considera-se que a constituição do trabalho do(a) professor(a) da hora-atividade está relacionada com as lutas históricas, em busca de uma Educação de qualidade e de melhores condições de trabalho. A singularidade desse docente está ligada com a relação universal do trabalho, assim, para compreender sua necessidade profissional, foi preciso abordar a construção educacional, em um cenário capitalista que não reconhece o valor do professor. Dessa forma, conhecer o trabalho do(a) professor(a) da hora-atividade, sendo esse uma especificidade da profissão docente, é fundamental para refletirmos sobre a organização pedagógica e as práticas realizadas em sala de aula, a fim de contribuirmos para a manutenção do pensamento crítico, com relação às abordagens de ensino, e para continuarmos buscando o aperfeiçoamento e a qualidade da relação ensino-aprendizagem das crianças pequenas. Por fim, o(a) professor(a) da hora-atividade está inserido(a) no contexto de sala de aula e é necessário averiguar de forma empírica as suas principais características.

Sugere-se que às pesquisas futuras, os pesquisadores que investigam a temática reflitam sobre a valorização e precarização do trabalho docente, a organização do ensino, as novas configurações que cercam a profissionalização e as lutas coletivas para a permanência desses trabalhadores na educação enquanto professores que garantem o direito da horaatividade e ao acesso à Educação Infantil de qualidade.

\section{Referências}

Araújo, F. da C. M. (2015). A Central Única dos Trabalhadores (CUT) e seu Arquivo: a importância da documentação no processo de construção da memória (1983-2003). Revista Científica Vozes dos Vales-UFVJM-MG -Brasil - No 07-Ano IV-05/2015. Recuperado de <www.ufvjm.edu.br/vozes >

Brasil (2008). Lei $n^{o} 11.738$ de 16 de julho de 2008. Brasília: Senado Federal.

Brasil (1990). [Constituição (1988)]. Constituição da República Federativa do Brasil: promulgada em 5 de outubro de 1988. (4a ed.) São Paulo: Saraiva.

Beaud, M. (1987). História do capitalismo: de 1500 aos dias de hoje. São Paulo: Editora Brasiliense. 
Bobbio, N., Matteuci, N., \& Pasquino, G. (1995). Dicionário de Política. 8.ed. Distrito Federal: Editora Universidade de Brasília.

Czekalski, R. A. (2008). A apropriação da hora-atividade como espaço de formação de professores em serviço: um estudo sobre organização do trabalho docente em Telêmaco Borba. Londrina: Universidade Estadual de Londrina.

Dieese (2019). Estudos Socioeconômicos, Família assalariada: padrão e custo de vida. São Paulo, 1(2).

Engels, Friedrich (2008). Os sindicatos. In: Aguena, Paulo (Org.). O Marxismo e os Sindicatos. São Paulo: Sudirman.

Engels, F. (1986). O papel do trabalho na transformação do macaco em homem. (3a ed.) São Paulo: Global editora. In: Marx, Karl \& Engels, Friedrich. Textos. São Paulo: Edições Sociais.

Gil, A. C. (1999). Métodos e técnicas de pesquisa social. (5a ed.) São Paulo: Atlas.

Goettert, J. D. (2014). Introdução à história do movimento sindical. (3a ed.), $1^{\text {a }}$ Reimp: Brasília, DF: Confederação Nacional dos Trabalhadores em Educação.

Lima, T. C. S., \& Mioto, R. T. (2007). Procedimentos metodológicos na construção do conhecimento científico: a pesquisa bibliográfica. Katál, Florianópolis, 10, 37-45.

Martins, H. H. T. de S. (2004). Metodologia qualitativa de pesquisa. Educação e Pesquisa, São Paulo, 30(2), 289-300Recuperado de 〈http://www.scielo.br/pdf/ep/v30n2/v30n2a07.pdf>

Maringá (1988). Lei no 272 de 22 de dezembro de 1998. Maringá: Câmara de vereadores do Município de Maringá.

Maringá (1988). Lei complementar $n^{\circ}$ 790. Maringá: Câmara de vereadores do Município de Maringá. 
Marx, K. (1985). O Capital: crítica da economia política. Tradução por Regis Barbosa e Flávio R. Kothe. São Paulo: Abril Cultural, Livro 1, 1.

Marx, K. (2008). As greves e as coligações de operários. In Aguena, Paulo (Org.). O Marxismo e os Sindicatos. São Paulo: Sundermann.

Marx, K. (1983). Contribuição à Crítica da Economia Política. São Paulo: Martins Fontes.

Marx, K. (1978). Manuscritos econômico-filosóficos e outros textos escolhidos. Os pensadores. São Paulo: Abril Cultural.

Marx, K. (2009). Manuscritos econômicos-filosóficos. Tradução Jesus Ranieri. São Paulo: Boitempo.

Mattos, M. B. (2009). Trabalhadores e sindicatos no Brasil. SP: Editora Expressão Popular.

Paraná (2002). Lei Ordinária $N^{o}$ 13807, de 30 de setembro de 2002. Curitiba: Estado do Paraná.

Paraná (2004). Lei Complementar $N^{o}$ 103, de 15 de março de 2004. Curitiba: Estado do Paraná.

Prado, Eleutério F. S. Duas explicações marxistas para a grande falha do capitalismo. Recuperado de< http://eleuterioprado.wordpress.com>

Proni, M. W. (1997). História do capitalismo: uma visão panorâmica. Cadernos do CESIT, Campinas, n.25. Recuperado de http://www.cesit.net.br/cesit/images/sories/25Cade rnosdoCESIT.pdf>

Schlesener, A. H., Gisele, M., Subtil, M. J. D. (2016). Marxismo(s) e educação (Org.). Ponta Grossa: Ed. UEPG.

Vygotsky, L. S. (1991). A formação social da mente. São Paulo: Martins Fontes. 
Teixeira, R. D. (2009). Para onde foi a cut? do classismo ao sindicalismo social-liberal (1978-2000). Rio de Janeiro: Universidade Federal Fluminense.

Vázquez, A. S. (1978). As ideias estéticas de Marx. Rio de Janeiro: Paz e Terra.

\section{Porcentagem de contribuição de cada autor no manuscrito}

$$
\text { Amanda Vitor Dourado - 60\% }
$$

Silvia Pereira Gonzaga de Moraes - 40\% 